\title{
“¿Pedir disculpas?, “¡ipor qué!?”. Del bullying al moving: violencia desde la casa hacia la escuela y el trabajo
}

\section{Introducción}

Una hipótesis bastante sencilla y hasta cierto punto simplista consiste en relacionar mecánicamente y trasponer de modo causal el contexto de violencia de la casa y la familia con el de la escuela y luego el del trabajo (Espósito, 2006). Desde esta perspectiva, resulta relativamente fácil, hasta cierto punto, sacar conclusiones redundantes y obvias de la violencia y su relación entre los ambientes familiares, laborales, escolares y educativos (Espósito, 2006). Una tarea mucho más complicada es develar el tejido psicológico que entrelaza profundamente los entornos familiares y de crianza con las conductas de violencia en la escuela y de acoso laboral en las instituciones.

Precisamente, en este capítulo, desde tres historias de vida de dos profesoras y un empleado administrativo de la Universidad de Guadalajara, se irá tejiendo el entramado social y emocional de la violencia cotidiana, en sus propias palabras, desde su infancia y juventud, pasando por sus etapas educativas para culminar con su presente, como profesores o empleados de diferentes instancias educativas. 


\section{¿Pedir disculpas?, ¿¡por qué!?}

La señora Mary tiene poco más de 50 años; pese a la etapa de madurez en la que se encuentra, su cuerpo conserva aún, en alto porcentaje, la bella silueta de una mujer atractiva. Coronando su rostro de tez blanca con unos grandes ojos claros, seguros, vivaces e inteligentes. La frase “¿pedir disculpas?, ¿ipor qué!?” Pertenece a ella. Fue pronunciada con firmeza tras casi 20 años de servicio en la Universidad de Guadalajara como docente y empleada administrativa de confianza en esa casa de estudios, donde encontró su más importante medio de subsistencia, con el cual sostiene a su hijo, madre y hermano. Pero también aprendió y experimentó ahí, en carne propia a lo largo de todos esos años, el agudo filo de la violencia laboral, el ejercicio de un poder irracional y voluntarioso que llegó a afectar su vida más íntima, y el acoso institucional cotidiano sin razón ni lógica aparente:

¿Pedir perdón?, ¿pedir disculpas...?, ¿̇ipor qué...?!” Pedir permiso, solo cuando necesitas la aprobación de tus superiores o el consentimiento de tus compañeros, para hacer un trámite, solicitar el apoyo o ayuda de alguien de tu institución. ¿Pero pedir disculpas cuando no has hecho nada malo, e incluso estás haciendo bien tu trabajo...?, ¿ipor qué?! Esto último me lo exigieron desde un inicio en la Universidad. No está escrito, pero parece que es un requisito diario para sobrellevar tus relaciones con los demás. Yo trabajé en un montón de instituciones privadas antes de ingresar a la Universidad de Guadalajara, en ellas siempre encontré gente honorable y trabajadora que sabía muy bien cuál era su papel y su trabajo. Agradezco mucho todos estos años en la Universidad, pero la inmensa mayoría de las personas dentro de ella no saben trabajar en lo absoluto. La institución se sostiene por milagro. Transcurre toda una mañana en que las personas están sentadas en sus escritorios, sobre todo los funcionarios y la gente que se siente privilegiada por las administraciones en turno. Llegan tarde, hacen sus llamadas personales, toman café o refresco de soda, consultan un buen rato sus redes sociales, otras dos horas para desayunar, alguna junta o reunión cerca del medio día, y eso es todo. Puras relaciones públicas, o lo que llaman vulgarmente: grilla. La 
mayor parte del trabajo y del funcionamiento de un centro universitario se sostiene sobre los hombros de unos pocos, dos o tres cabezas sacrificadas y comprometidas, quienes sustentan toda la estructura laboral y, sobre todo, la de sus jefes. Te das cuenta que todo está dividido y repartido en cotos de poder, los que llegan alto, ya la hicieron.

Como se ha reiterado, las caras de la violencia suelen ser muy diversas. No es necesario agredir físicamente a alguien o arremeter verbalmente contra él o ella de modo directo para que este acto llegue a ser violencia. Hay formas muy sutiles donde la comunicación se distorsiona, se enmascara o transforma, siempre a favor de los que tienen el poder y la posibilidad de ejercerlo con violencia, a veces por el mero placer de hacerlo, sin razón aparente, o porque en su singular visión consideran que es parte del poder aplicar la violencia sobre quienes creen están por debajo de ellos:

Recuerdo un detalle muy simple, pero muy cruel. En los primeros años que trabajaba en la Universidad, estábamos colaborando con un equipo perteneciente a diversas instancias de la $\mathrm{U}$ de G; éramos como diez personas. Debíamos elaborar un documento en conjunto para una instancia universitaria. Cada quien debía elaborar un capítulo del texto, el cual requería mucha investigación, reflexión y escritura. Mi función, además de escribir, como todos, uno de los capítulos, era compilar y darle forma y unidad a todo el material. En una de las últimas reuniones conocí a una mujer, una doctora, con muchas credenciales y viajes en el extranjero, supuestamente. Solo hablamos una media hora, me resultó agradable en un inicio. Pues con esa media hora bastó para que la doctora me tomara la confianza suficiente para nunca enviarme la parte que le tocaba redactar. Le escribí varios correos electrónicos pero jamás recibí respuesta, llamé a su secretaria y la doctora nunca se encontraba ni mucho menos se reportó. Cuando faltaba poco tiempo para que se cerrara el plazo que teníamos fijado y entregar el producto final, ya todos los colaboradores me habían mandado su parte, menos ella. Entonces me tomé la confianza de llamar a su casa para tratar de localizarla. De nueva cuenta la doctora no 
estaba, pero me contestó su marido. Cuando me dijo que no se encontraba y que si deseaba dejarle un recado, me identifiqué y le pedí que le dijera que me mandara lo antes posible su capítulo. El señor me subió de inmediato el tono de voz, me dijo que si había algún problema con su esposa, que él se dirigiría al momento con el rector general de la Universidad. Me pidió mi nombre y me amenazó con hablarle al rector. Colgué y me dispuse a investigar y escribir de inmediato su parte, pues supe que jamás lo iba a hacer ella. Tragándome el llanto, el miedo y la humillación, ya que yo solo estaba cumpliendo con mi tarea.

¿Decirle al rector...? ¿Como para qué, para que me corriera...? ¿Por cumplir con mi trabajo...? El punto es: ¿Por qué aludir a la figura del rector general para sentirse más fuertes? ¿Por qué amenazar a una simple asistente, como yo, cuando yo se los estaba pidiendo en buen tono? Simplemente estaba cumpliendo con mi obligación. Además era trabajo de ella, para el cual se había comprometido... Después supe que su marido era también funcionario, era director de División. En el fondo se trataba de eso: ella no iba a realizar de ningún modo su trabajo y desde un inicio se pretendía que lo hiciera yo. No eran necesarias las amenazas personales ni la referencia a la autoridad del rector.

\section{La prostitución académica y administrativa}

La mezcla de las relaciones laborales con las personales y, más aún, con las íntimas e incluso las sexuales es algo que en algunos países, sobre todo del primer mundo, se encuentra prohibido o es mal visto. Contrariamente, como relatará la señora Mary, en la institución donde ella trabaja, parece un requisito imprescindible, por lo menos para el género femenino, el comercio sexual; es decir, el proporcionar favores sexuales a ciertos funcionarios si se desea ascender en el escalafón institucional. El relato de vida de la señora Mary prosigue, tocando puntos escabrosos: 
La U de G es una empresa misógina, si quieres subir tienes que acostarte con alguien, por lo menos esto es una realidad para las mujeres. Yo trabajé primero para una empresa para-universitaria, la cual es un brazo de la Universidad de Guadalajara. Entré a inicios de los años noventa, con muchas ganas y ánimos. Tenía ya bastante experiencia laborando para el Gobierno y para otras instituciones privadas: aseguradoras, financieras, bancos, así es que ayudé, capacité y enseñé a mucha gente, aunque jamás me pusieron un asistente ni ningún ayudante. Y desde un inicio me daba cuenta que las verdaderas oportunidades de ascenso laboral eran para los hombres. Si acaso una mujer quiere subir política o administrativamente, tendrá que ceder en la parte sexual ante sus jefes y ante los funcionarios educativos o políticos. Yo me considero aún una mujer guapa, y creo que en una época era muy bonita, por lo que desde joven nunca me faltaron las proposiciones sexuales ni las insinuaciones que más bien eran muy directas. Pero nunca accedí, tuve dos esposos y traté de permanecer fiel con cada uno de ellos en su momento, aunque al final me divorcié de ambos. También tuve varios jefes y compañeros de trabajo que trataron de obtener favores sexuales de mí, e incluso que los tuviera con sus respectivos jefes. ¡Imagínate! ¡Es una especie de red de prostitución universitaria! Los subalternos tratan de mandarles las mujeres a los funcionarios para que se sirvan sexualmente de ellas, como si fueran una mercancía que les pertenece a todos. Pero yo jamás accedí. Por lo tanto, siempre estuve congelada laboralmente, eso sí, con muchísimo trabajo y responsabilidades. Debido a mi seriedad y a mi negación a involucrarme en aspectos íntimos con mis jefes, siempre me tuvieron marginada. A tal punto que en el año 2011 me quitaron todas mis prestaciones, por decisión de un director, perdí mi antigüedad en la Universidad y con toda la posibilidad de algún día encontrar una base e incluso pensionarme cuando ya no pueda trabajar.

El Ministerio de Trabajo de la Unión Europea define algunas características indispensables para caracterizar como acoso sexual en el trabajo a este fenómeno: 
a. Es una conducta indeseada, irrazonable y ofensiva para la persona que es objeto de esta.

b. La negativa de dicha persona es tomada, explícita o implícitamente, como pretexto para obstaculizar su desarrollo, crecimiento, capacitación y prosperidad económica.

c. Es parte de un entorno laboral hostil y humillante (Instituto de Seguridad e Higiene en el Trabajo de España, 1999).

Las experiencias relatadas por la señora Mary caben perfectamente en la categoría definida por la Unión Europea como acoso sexual en el trabajo, en primer lugar por su negativa a ceder ante las solicitudes sexuales de sus jefes y compañeros, lo cual truncó, en buena medida, su carrera laboral dentro de la Universidad, e incluso, perdió, de modo indirecto, en un momento dado, todas sus prestaciones y antigüedad dentro de la institución. Culminó en un "congelamiento", donde aunque la persona no es despedida ni separada de la institución, se le impide su crecimiento económico e, incluso, se le obstaculiza su desarrollo en el trabajo.

\section{Olvidada por su abuela, quien adoraba a sus hermanos: misoginia familiar e institucional}

La señora Mary prosigue con su relato de vida, en el que conecta la misoginia vivida en su infancia con la que le tocó experimentar en su institución de trabajo:

Yo siempre fui muy alegre y amiguera. Eso me ayudó bastante a sobrevivir todos esos años en diversas instancias de la Universidad. Pero también me he dado cuenta de que las cosas que me han sucedido dentro del trabajo se parecen a las que he vivido desde niña con mi familia. Yo era la única mujer en mi casa, con tres hermanos más, así es que siempre me enseñaron a servir a los hombres, a ser muy obediente y solícita con ellos. Yo cocinaba, lavaba y servía a mis hermanos desde niña. Tengo presente un recuerdo muy doloroso que aún me cuesta trabajo mencionar: cuando se enfermó y falleció el menor de mis hermanos, mis papás se fueron 
al hospital con él y me dejaron con mis otros dos hermanos. Yo tenía seis años, entonces vino mi abuelita a recoger a mis otros dos hermanos, pero se olvidó de mí. ¿Puedes creer eso? ¿Dejar sola a una niña de 6 años? Recuerdo que desperté en la madrugada y no había absolutamente nadie. Siempre me sentí marginada como mujer. Entonces entro a la Universidad de Guadalajara a trabajar y sigo viviendo mucha discriminación como mujer. Mis hermanos siempre fueron la adoración de mis abuelas y de mis papás. Hasta la fecha mi madre y mi hermano solo me buscan cuando necesitan mi ayuda económica o algún favor, pero nada más. Como que creen que es mi obligación aunque ellos se porten como se portan conmigo: hay mucha falta de respeto y mucha humillación de parte de ellos.

Un capítulo bien triste para mí fue en una ocasión en que jugaba el equipo de fútbol de la U de G. En esa ocasión ganaron, así es que yo había conseguido unos boletos para mí y mi hijo. A la hora de la celebración, bajé como todos los empleados de la Universidad, a celebrar con él a la cancha, y entonces que me ve una de las funcionarias de una instancia universitaria donde en ese entonces trabajaba. Y que me toma del brazo y me dice: “¡No, tú no puedes estar aquí...!” Y me sacó casi arrastrándome por el brazo con todo y mi hijo. Fue uno de los capítulos más humillantes que he vivido en mi historia laboral.

Como lo describe la señora Mary, desde niña vivió la preferencia de sus padres y abuelas hacia sus hermanos, a tal grado que en una ocasión, la olvidaran por completo en su casa, durante la madrugada. Un escenario análogo encuentra en la Universidad, un entorno que privilegia, por completo, según sus palabras, a los hombres. El cuestionamiento más interesante es si es el entorno el que atrae y moldea a las personas hacia ambientes de violencia y discriminación, en este caso sexual, o si las personas, con su actitud y desarrollo emocional, buscan indirectamente este tipo de escenarios, los crean o co-crean a partir de sus vivencias, representaciones y creencias.

Algo que tienen en común ambos entornos, la familia y el trabajo, es la sensación de desolación y abandono que vive la persona, en este 
caso Mary, quien se siente por completo desprotegida y abandonada en el entorno laboral, donde no tiene amigos ni cuenta con el apoyo de nadie, del mismo modo que lo vivió en la infancia; abandonada por sus padres y abuela, marginada por su madre y sus hermanos.

\section{Lo más fuerte ocurrió en la primaria}

Rony es un chico de 19 años de edad, estudiante de Administración Pública, quien actualmente se desempeña como becario para la Rectoría General de un centro universitario, al interior de la Universidad de Guadalajara. Rony recibe un pequeño salario quincenal al mismo tiempo que culmina sus estudios de licenciatura y también se capacita laboralmente. Es de tez muy morena y algo pasado de peso. Cuenta que desde niño nació con una singularidad genética: sus pechos eran muy grandes para ser varón, por lo cual recibió burlas y acoso desde la etapa de la escuela primaria; lo tildaban de ser mujer u homosexual, situación que se extendió y prolongó hasta su actual etapa laboral dentro de la Universidad de Guadalajara:

Lo más fuerte me pasó en la primaria. Era el inicio de los años 2000 y estaban de moda los videojuegos, las películas de animé y las mangas japonesas. A mí y a otro compañero nos gustaban mucho, pero por esa razón siempre nos marginaban y nos veían como raros. Todos, absolutamente todos en el salón nos agredían: nos pateaban las cartitas de manga, escondían nuestras mochilas, en una ocasión me vaciaron en el brazo una sopa maruchan hirviendo. A veces me duele recordar que yo no tuve una época bonita de la escuela primaria, ni mucho menos de la secundaria. La mayoría de la gente recuerda estas etapas con mucho agrado y nostalgia, pero yo no, y eso me duele mucho.

En secundaria entré a la Técnica no. 4 que está en la colonia Jardines del Country. Esa época fue horrible, mi amigo Carlitos y yo éramos catalogados como los “ñoños”. Un ñoño es un niño que se esfuerza mucho por obtener las mejores calificaciones, que tiene gustos diferentes a sus compañeros tanto en la música, como 
en películas, videojuegos, etcétera. Por lo tanto, al ser diferente, es atacado y marginado por sus compañeros de clase.

Había un niño en segundo de secundaria que se llama Christian, que siempre me pegaba a mí y a mis amigos. Me ponía polvos pica-pica en el sillón, un día le pegó con un tira-pedos a mi amigo Carlitos. Un tirapedos es una pequeña arma hecha con un globo grande, adherido al tuvo de una cinta diúrex o al cuello de un bote de plástico recortado. Con él se pueden disparar frijoles, garbanzos con pólvora y piedras. Con él le pegó Christian a Carlos en la espalda y lo hizo llorar muchísimo. Entonces no me pude aguan$\operatorname{tar}$ y que le suelto un trancazo en la cara, bien duro a Christian, en la pura nariz. Le sangró y nunca se volvió a meter con nosotros. Desde entonces siempre he sentido el impulso de defender a los niños y a las personas que son abusadas.

Es curioso, pero con el paso de los años, volví a encontrar a Christian, nos vimos en un camión del transporte público y le platiqué que estaba terminando mi licenciatura y toda la cosa. Y cuando me dijo que él era cargador en el Mercado de Abastos, en el fondo me alegré y pensé: “iToma, pagaste todo lo que me hiciste...!”.

La persona que ha vivido el acoso y la violencia cotidiana desde épocas tempranas, primero en la escuela y luego en el trabajo, va generando una conciencia de marginación; se siente diferente a los grupos dominantes, rechazado por ellos; al vivir agresiones no solo verbales, sino también físicas, acumula recelo y resentimiento, al mismo tiempo que logra identificarse con aquellos pertenecientes a otras minorías y grupos rechazados; incluso se plantea la idea de defenderlos y luchar hasta cierto punto por ellos:

En otra ocasión, en segundo grado de secundaria, una niña me retó a golpes, quería que nos "aventáramos un tiro". Todo sucedió porque ella primero me puso muchísimo lápiz labial en la butaca durante el recreo, para que cuando yo regresara, me manchara todo el uniforme blanco de deporte. Entonces, lo que hice fue tomar simplemente mi butaca ensuciada por ella y cambiarla por 
la suya. Cuando se acabó el recreo y todos estaban a la espera de que cayera en su broma estúpida, ella fue la que comenzó a lloriquear y quejarse con la maestra de que se había manchado. Pretendió echarme a mí la culpa, desde luego, pero hablando con la profesora todo se aclaró y se demostró que fue ella quien manchó la banca con la intención de mancharme. Entonces se me abalanzó para querer golpearme y me retó a golpes al finalizar la escuela. Obviamente que no accedí y me largué de inmediato.

\section{Ser amigo de los amigos de mis amigos}

En su clásico libro, Psicología social de las minorías activas, Serge Moscovici (2001) sugiere que las minorías y los grupos marginados y relegados enfrentan una ambivalencia que los supera: por una parte, viven la diferencia y el rechazo de los grupos dominantes o detentadores del poder; experimentan el rechazo y acumulan, por su parte, el correspondiente resentimiento e, incluso, odio. Pero, por su parte, estas minorías activas, como las denomina Moscovici (2001), alimentan también una nostalgia y hasta cierta envidia hacia los grupos, las instituciones e instancias que los relegan y no los aceptan. En el fondo, desearían pertenecer a ellas, aunque por sus vivencias, experimentan ideas de venganza hacia aquellas. Se trata de una relación de odio-resentimiento-amor-envidia-nostalgia.

El trabajo de Moscovici se desenvolvió en Francia en los años sesenta y setenta, cuando fuertes oleadas migratorias provenientes del norte de África y de Medio Oriente, tras las guerras en Marruecos, Túnez, Líbano, etc., arrastraron a miles de familias e individuos provenientes de aldeas devastadas por los movimientos armados y las invasiones de aquellas décadas, cruzando el Mediterráneo desde sus continentes para ir hacia el Primer Mundo.

Grupos enteros con mentalidades aún tribales y religiones islámicas integristas llegaron a las grandes capitales de Europa, fracasando en su integración y asimilación a las nuevas culturas. Añoraban una vida más segura y relajada económicamente, pero, al mismo tiempo, odiaban a las sociedades colonialistas que en el fondo generaron las catástrofes de sus países y regiones. Todo ello dio como resultado los actuales movimientos terroristas que ponen en jaque 
a las policías y servicios secretos de Europa, orquestados en muchas ocasiones por miembros de segunda y tercera generación de migrantes de Asia y África, quienes no han sido asimilados culturalmente del todo por las sociedades europeas, ni tampoco, en el fondo, desean hacerlo.

Esta conceptualización de Moscovici resulta útil para entender a otros grupos marginados dentro de la escuela y el trabajo: los "ñoños”, los "nerds", los "homosexuales", etc., los cuales han sufrido violencia, acoso y marginación. Por si fuera poco, tampoco son aceptados por la cultura dominante en la escuela y las instituciones laborales, pero, en el fondo, añoraran pertenecer a ella, aunque quizá no lo reconozcan. $\mathrm{Al}$ respecto, el relato de Rony prosigue y a ratos se vuelve desgarrador:

Siempre quise saber lo que se sentía ser en verdad amigo de alguien. Tenía algunos compañeros desde la secundaria y la prepa, y ahora con el Facebook nos hemos reencontrado. Pero nunca tuve un grupo con el cual me identificara y con quienes salir los sábados. Me moría cada fin de semana porque alguien me invitara al cine o a pasear a alguna plaza. Pero parece que yo alejaba a la gente, o que cuando yo quería invitarlos a alguna parte, nadie podía. Obvio que tampoco nadie me invitaba a mí. En una ocasión organicé una fiesta de cumpleaños en un café-bar en Chapultepec, mi mamá me dio dinero para planearla, invité como a veinte personas y nadie fue. Me quedé sólo con mi mama. En ese momento no dije nada, pero regresé a casa y lloré toda la noche. Te lo juro que llegó un momento que quería conseguir una pistola y llegar un día y balacear a todos mis compañeros. Cuando leía las noticias de que alumnos llevaban una ametralladora a sus escuelas en Estados Unidos y la vaciaban sobre sus compañeros y sus maestros, yo los entendía. Porque la mayoría de los maestros también eran cómplices de estas burlas, o las toleraban y se reían hasta cierto punto.

En la preparatoria fue lo mismo. Sólo que por una cuestión genética yo tenía los pechos grandes, así nací. Y en esa época se me notaban mucho. Entonces siempre caminaba agachado para 
que nadie me los viera, porque si no, decían que yo era mujer. El resultado fue que me salió una joroba de tanto estar agachado. Un día en un paseo en el club de la U de G, me metí a bañar y los compañeros se me quedaron viendo con horror, como si contemplaran a una criatura asquerosa o a un fenómeno. Me salí de inmediato y me encerré a llorar en el baño.

Hasta últimamente, en la Universidad encontré a un pequeño grupo de amigos que no sólo me buscan por algún interés: que les preste dinero o que los ayude con las tareas. Un amigo me llevo a mi casa en su coche, luego me invitó al cine con su novia y otros amigos, nos la pasamos tan bien, que al final dije: “Ah, así es como se siente tener amigos, que te quieran y que te inviten..."

Para mí, pertenecer realmente a un grupo de amigos es cuando no sólo eres amigo de uno sólo, sino que este te presenta a sus amigos y al rato eres amigo de sus amigos también. Y ellos se preocupan por ti y realmente quieren estar cerca de ti.

\section{Castigarte solo porque eres diferente}

La maestra Noelia entró a trabajar al Colegio Católico en Guadalajara para relevar a su hermano, quien a su vez consiguió otro trabajo en el Gobierno municipal. Ella es licenciada en letras, así que hacerse cargo de las materias de historia, español y lectura la entusiasmó en un inicio. No le dijeron cuando la contrataron que el colegio poseía una ideología católica ultraconservadora, incluso ortodoxa y tradicionalista dentro del mismo catolicismo, sino que lo tuvo que ir descubriendo poco a poco, de una manera a veces bastante dolorosa.

Noelia ya tenía bastante experiencia en otras tres escuelas como docente, en primaria y bachillerato, tanto en colegios pertenecientes a la enorme capital de Guadalajara, como en pequeños poblados del norte de Jalisco. Al igual que la señora Mary, la empleada de la Universidad de Guadalajara, Noelia señala haber vivido una marcada discriminación en las escuelas por el simple hecho de ser mujer: 
El primer recuerdo que tengo de acoso laboral o de discriminación en el trabajo fue en la preparatoria del municipio de Santa María de los Ángeles. Yo me había ganado mis clases por concurso de oposición, pero el director a fuerzas le quería dar las mías precisamente a un exalumno suyo que trabajaba en el Gobierno municipal, él era contador público, no cubría con el perfil para dar clases de humanidades. Pero el director quería que se quedara él, y a mí me obligó a hacer los exámenes psicopedagógicos dos veces con la esperanza que los reprobara, su tirada era que se quedara su amigo y no yo. Pero logré pasar bien los exámenes y quedarme con mi lugar. Por eso el director nunca me quiso. Siempre me perdían mis listas de calificaciones o mis cheques. Con las mujeres era bien exigente, pero como se llevaba muy bien con los hombres y tenía muchos amigos en la política, a ellos les daba bastante preferencia y esto se notaba. Era muy claro, a sus amigos hombres les pasaba las clases sin obligarlos a hacer exámenes en Guadalajara, como sí lo hacía con las maestras grandes y con las recién egresadas.

Pero donde más claro he vivido el hecho de que se metan conmigo, hasta lo más profundo de mi intimidad, fue en el Colegio. Siempre hubo un trato muy frío hacia mí y hacia la mayoría de los profesores, se notaba muy claro que había preferencias hacia unos pocos maestros y profesoras que tenían muchos años trabajando ahí y que hacían todo lo que se les pedía sin protestar.

En una ocasión me mandaron llamar para regañarme sin que yo lo esperara, la dueña del colegio me gritó fortísimo, como si fuera yo una niña, porque una de las alumnas llevo el libro de Carry, de Stephen King. Ese libro es un clásico ya de la literatura universal, aunque pertenece al género de horror. Pero no es nada malo que los adolescentes lo lean. La dueña y la directora me dijeron que ya me fuera despidiendo porque me iban a correr, que yo representaba un peligro para los muchachos del colegio. Después me di cuenta que varios de los profesores se dedican a llevarle 
chismes y habladurías aunque no sean ciertas y de esta manera quedan bien con ella.

Y ese ha sido siempre el problema en ese Colegio, el punto es que si quieres hacer bien tu trabajo y hacer bien las cosas, pues marcas una diferencia, y ser diferente está penado.

Me he dado cuenta que en ese Colegio puedes ser atacado y castigado simplemente por el hecho de hacer bien tu trabajo.

En su estudio, Moscovici (2001) señala que para pertenecer a una minoría, el individuo debe poseer ciertos rasgos o características que lo hagan diferente del resto de sujetos pertenecientes a la mayoría. Puede tratarse de un rasgo físico, como el caso de Rony, pasando por la apariencia: una mujer atractiva puede llegar a sufrir una doble marginación, por una parte, por el simple hecho de ser mujer y, por último, si no accede a los deseos sexuales de sus jefes y compañeros, como es el caso de la señora Mary. También, puede ser una cuestión de género: ser mujer, homosexual, etc., o un asunto racial, dependiendo del lugar o país de procedencia, así como de la raza y la religión.

Pero en el caso de la maestra Noelia, el realizar su trabajo al interior de una institución, de una manera que marca diferencias con respecto a los demás, aunque esto hipotéticamente sea para bien, puede llamar la atención y generar agresiones y discriminación por parte de sus compañeros y jefes. Pareciera que en varias instituciones predominara la inercia y la mediocridad laboral, de modo que realizar cosas que puedan resultar innovadoras o marcar una diferencia, la cual llevará a hacer bien su trabajo o mejor que los demás, también puede producir acoso y discriminación.

Resulta duro y sorprendente, a la vez, encontrar panoramas laborales y educativos en México donde es penado proponer e innovar. La profesora Noelia señala que incluso se le ha reprochado por parte de sus compañeros el hecho de llegar siempre temprano para trabajar. Como si por eso se pusiera en evidencia que el resto no lo hace. 


\section{Bibliografía}

Espósito, R. (2006). Lenguaje y violencia, entre Benjamín y Canneti. Revista de Filosofia.

Instituto de Seguridad e Higiene Laboral de España. (1999). Sexual harassement in the work place. España.

Moscovici, S. (2001). Psicología social de las minorías activas. España: Ed. Nueva Visión. 
